\title{
Establishment and characterization of seven human breast cancer cell lines including two triple-negative cell lines
}

\author{
JA-LOK KU ${ }^{1,5^{*}}$, SUNG-CHAN PARK ${ }^{2 *}$, KYUNG-HEE KIM ${ }^{1}$, YOU-KYUNG JEON ${ }^{1}$, SUNG-HEE KIM ${ }^{1}$, \\ YOUNG-KYOUNG SHIN ${ }^{1}$, DONG-YOUNG NOH ${ }^{2}$, SEOCK-AH IM ${ }^{3}$, YUNG-JUE BANG ${ }^{3}$, \\ WONSHIK HAN ${ }^{3}$, WOO HO KIM ${ }^{4}$ and JAE-GAHB PARK ${ }^{1,2}$ \\ ${ }^{1}$ Korean Cell Line Bank, Laboratory of Cell Biology, Cancer Research Institute, ${ }^{2}$ Department of Surgery, \\ ${ }^{3}$ Division of Hematology and Medical Oncology, ${ }^{4}$ Department of Pathology and ${ }^{5}$ Department of Biomedical Biosciences, \\ Seoul National University College of Medicine, Seoul 110-744, Republic of Korea
}

Received July 27, 2013; Accepted September 23, 2013

DOI: $10.3892 /$ ijo.2013.2144

\begin{abstract}
Permanently growing cell lines can be invaluable because of their usefulness in a variety of experimental situations. We report the characteristics of seven cell lines designated, SNU-306, SNU-334, SNU-1528, SNU-1553, SNU-1581, SNU-1958 and SNU-2372, which were established from three primary carcinomas, two pleural effusion, one pericardial effusion and one ascitic fluid samples obtained from seven Korean breast carcinoma patients. The histopathology of the primary tumors and their in vitro growth characteristics are described. DNA fingerprinting analysis and genetic alterations in the p53 and EGFR genes were conducted. The expression levels of the $E R-\alpha, P R, C$-erbB2, E-cadherin, $C O X-2$, $M D R$ and $M X R$ genes were investigated and sensitivity to anticancer drugs was screened. Growth was as adherent cells (four cell lines), floating aggregates (one cell line) and both (two cell lines). All lines were free of mycoplasma or bacteria and were proven unique by DNA fingerprinting analysis using 18 microsatellite markers. Estrogen receptor (ER) mRNA was highly expressed in five cell lines and low or undetectable in SNU-1958 and SNU-2372. Progesterone receptor (PR) mRNA was expressed only in the SNU-306. SNU-1958 and SNU-2372 were hormone receptor-negative and C-erbB2negative (triple-negative). SNU-1528 had an in-frame deletion of 42 base pairs of $p 53$ gene and showed over 20-fold resistance for taxol compared to the other cell lines. There were no mutation in the EGFR gene; $C O X-2$ was expressed in four cell lines and $M X R$ was expressed in two cell lines. These wellcharacterized seven breast cancer cell lines, which include
\end{abstract}

Correspondence to: Dr Jae-Gahb Park, Laboratory of Cell Biology, Cancer Research Institute, Seoul National University College of Medicine, Seoul 110-744, Republic of Korea

E-mail: jgpark@plaza.snu.ac.kr

*Contributed equally

Key words: breast cancer, cell lines, establishment, triple-negative two triple-negative cell lines, will be useful for the study of breast cancer biology.

\section{Introduction}

Breast cancer is a heterogeneous disease, and it has long been appreciated that tumors with different biological features have different clinical outcomes and responses to therapy. At present, prognosis and treatment selection in breast cancer are based on characterization of tumor growth factor receptor status involving estrogen receptor (ER), progesterone receptor (PR) and C-erbB2. These markers can be used to define four functional groups of tumors: i) hormone receptor-positive; ii) C-erbB2-negative; iii) hormone receptor-negative, C-erbB2-negative (triple-negative tumors); and iv) C-erbB2 overexpressing tumors with or without hormone-receptor expression (1).

Triple-negative breast cancer, which is defined as being negative for ER, PR and C-erbB2, is associated with aggressive clinical behavior and poor prognosis. These cancers have become the subject of research interest because they do not benefit from hormonal therapies or treatments targeted against C-erbB2 receptors, and because they appear to be prevalent in breast cancer; one study reported 25 triple-negative cell lines out of 51 breast cancer cell lines that were examined (2). These triple-negative cell lines will be useful in research on tumor biology that relates to aggressive clinical behavior and poor prognosis of the tumors, as well as prediction of response to therapy and discovery of new therapeutic targets.

Breast tumor cells frequently co-exist with surrounding stroma such as normal epithelial, fibroblast and mesothelial cells $(3,4)$. Many breast tumor derived cell lines have been established from metastatic tumors, raising questions as to their relationship to primary tumors (3). This is clearly unrepresentative of the diverse types of tumor reflected by the specific types, various grades or stages and indications for tumor progression that are observed in primary breast cancer. For these reasons it would be more clinically relevant to use cells that are derived directly from a primary tumor, that is the target of most drug therapies (5). 
We report the characterization of seven human breast cancer cell lines designated SNU-306, SNU-334, SNU-1528, SNU-1553, SNU-1581, SNU-1958 and SNU-2372 including two triple-negative cell lines (SNU-1958 and SNU-2372), which were derived from three primary breast carcinomas, two pleural effusions, one pericardial effusion, and one ascitic fluid obtained from Korean breast carcinoma patients.

We describe the cell phenotypes including the histopathology of the primary tumors and their in vitro growth characteristics; DNA fingerprinting analysis to verify the authenticity of each of the seven breast cancer cell lines; expressions levels of $E R-\alpha, P R, C$-erbB2, E-cadherin, $C O X-2$, $M D R$ and $M X R(B C R P)$ genes; and alteration of $p 53$ and epidermal growth factor receptor $(E G F R)$ genes.

\section{Materials and methods}

Cell line establishment and maintenance. Cell lines were established from three primary breast carcinomas, one pleural effusion and one pericardial effusion of breast carcinomas. Solid tumors were finely minced with scissors and dissociated into small aggregates by pipetting. Appropriate amounts of finely minced neoplastic-tissue fragments were seeded into $25-\mathrm{cm}^{2}$ flasks. Pleural effusions were collected, pelleted, washed and resuspended in growth medium. Tumor cells were initially cultured in ACL-4 medium supplemented with 5\% heatinactivated fetal bovine serum (6-8). After establishment, these cell lines were maintained in RPMI-1640 containing $10 \%$ heat-inactivated fetal bovine serum. Initial cell passages were performed when heavy tumor cell growth was observed and subsequent passages were performed every one or two weeks. Adherent cultures were passaged at subconfluence after trypsinization. Cultures were maintained in humidified incubators at $37^{\circ} \mathrm{C}$ in an atmosphere of $5 \% \mathrm{CO}_{2}$ and $95 \%$ air. Breast cancer cell lines MCF-7, MDA-MD231 and SK-BR3 obtained from the Korean Cell Line Bank were used as polymerase chain reaction $(\mathrm{PCR})$ controls.

Growth properties and morphology in vitro. Population doubling times were determined by seeding $0.5-3 \times 10^{5}$ viable cells into $25-\mathrm{cm}^{2}$ flasks and counting daily for at least 14 days Cultures were fed every three or four days and $24 \mathrm{~h}$ prior to counting. Cell viability was determined by a dye-exclusion method using $0.4 \%$ trypan blue. PCR and microscopic examination were used to test for mycoplasma (e-Myco Mycoplasma Detection kit; Intron Biotechnology, Gyonggi, Korea) or bacterial contamination, respectively. For morphological studies, cells were grown on $75-\mathrm{cm}^{2}$ culture flasks and observed daily by phase-contrast microscopy.

Nucleic acid isolation and cDNA synthesis. Genomic DNA and total RNA were isolated from washed cell pellets. Total genomic DNA was extracted according to a standard sodium dodecyl sulfate-proteinase $\mathrm{K}$ procedure, and total cellular RNA was extracted according to the manufacturer's instructions (Intron Biotechnology). For cDNA synthesis, $2 \mu \mathrm{g}$ of total RNA was reverse transcribed using random oligo (dT) primer, dNTPs, and $1 \mu \mathrm{l}$ (200 units) of Superscript ${ }^{\mathrm{TM}}$ II reverse transcriptase (Life Technologies, Frederick, MD, USA) in a final volume of $20 \mu \mathrm{l}$ for $75 \mathrm{~min}$ at $42^{\circ} \mathrm{C}$ after a 10 -min dena- turation at $70^{\circ} \mathrm{C}$. A total of $80 \mu \mathrm{l}$ of distilled water was then added to the reverse-transcription reaction mixture.

DNA profiles. DNA was PCR amplified at loci containing the highly polymorphic microsatellite markers D1S1586 and D3S1765. PCR products were denatured using 95\% formamide and electrophoresed on a sequencing gel for $2 \mathrm{~h}$ at a constant $60 \mathrm{~W}$. Gels were dried and visualized autoradiographically. DNA was also amplified using AmpFlSTR identifiler PCR amplification kit (Applied Biosystems, Foster City, CA, USA). PCR amplified 15 tetranucleotide repeat loci and gender determining marker at loci containing highly polymorphic microsatellite markers. Amplified products were analyzed using an ABI 3730 Genetic analyzer (Applied Biosystems).

Expression of ER- $\alpha, P R, C$-erbB2, COX-2 and E-cadherin genes. For the mRNA expression analysis of $E R-\alpha, E R-\beta$ (9), $P R$ (10), C-erbB2 (11), E-cadherin (12), COX-2 (13), MDRl (14) and MXR (15) genes in the seven cell lines, cDNA was amplified in $25 \mu \mathrm{l}$ of a PCR reaction mix using $1 \mu \mathrm{l}$ of reverse-transcription reaction, primers and 0.5 units of Taq DNA polymerase. PCR amplification was carried out in a programmable thermal cycler. Primers for $\beta$-actin were used to confirm RNA integrity. Both genes and $\beta$-actin RT-PCR reactions used the same cDNA synthesis. Amplified DNA fragments were fractionated in a $2 \%$ agarose gel and stained with ethidium bromide.

Western blot analysis. Western blot analysis was performed as described previously (16). Briefly, cell homogenates containing equivalent amounts of protein were centrifuged at 4,000 $\mathrm{x} \mathrm{g}$, and the supernatant fractions subjected to SDS-PAGE. Following electrophoresis, proteins were transferred to polyvinylidene fluoride (PVDF) membranes (Millipore, Billerica, MA, USA) blocked by incubation for $2 \mathrm{~h}$ at $48^{\circ} \mathrm{C}$ in $1 \%$ Tween-20-TBS buffer containing $1.5 \%$ non-fat dry milk (Bio-Rad, Hercules, CA, USA) and $1 \mathrm{mM} \mathrm{MgCl}$. Membranes were incubated for $2 \mathrm{~h}$ at room temperature with primary antibodies against progesterone receptor (Ventana, Tucson, AZ, USA), estrogen receptor $\alpha, \mathrm{C}$-erbB2 (both from Dakocytomation, Carpinteria, CA, USA), or actin (Sigma-Aldrich, St. Louis, MO, USA). Next, membranes were washed for $3 \times 15$ min with blocking solution, and incubated with diluted HRP-conjugated secondary antibody (Southern Biotech, Birmingham, UK) for $1 \mathrm{~h}$ at room temperature. This was followed by washing with blocking solution (3x15 min), incubation with WEST-ZOL plus chemiluminescence reagent (Intron Biotechnology) for $1 \mathrm{~min}$, and exposure to film (Kodak Blue XB-1).

Detection of alterations in the p53 and EGFR genes. Mutational screening of exons 4-8 of p53 was performed by direct sequencing analysis. Oligonucleotide primers for the genomic PCR and PCR procedures were as described previously (17). Mutations of EGFR were also screened through exons 18-24 by direct sequencing analysis (18). PCR reactions were carried out in $25 \mu \mathrm{l}$ containing $100 \mathrm{ng}$ genomic DNA, 2.5 pmoles of each primer, four dNTPs at $250 \mu \mathrm{M}$ each, 0.5 units of Taq polymerase and PCR reaction buffer. Reactions were initiated by denaturation for $5 \mathrm{~min}$ at $94^{\circ} \mathrm{C}$ and amplification was conducted over 35 cycles in a programmable 


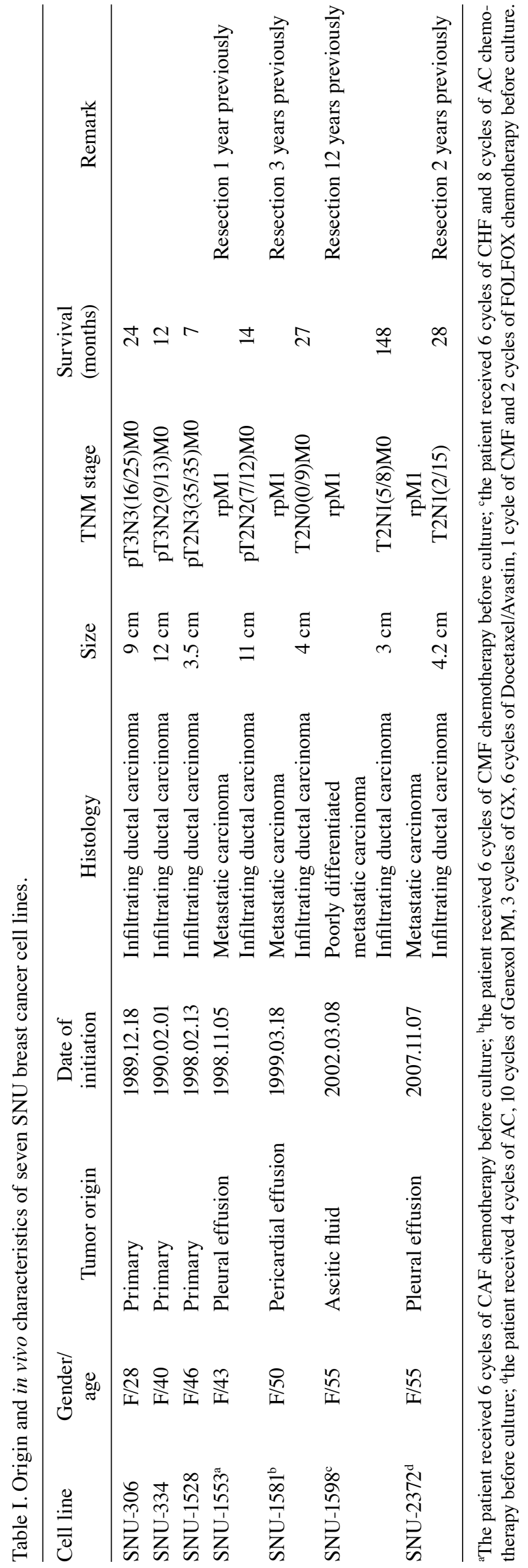

Table II. In vitro characteristics of seven SNU breast cancer cell lines.

\begin{tabular}{|c|c|c|c|c|}
\hline Cell line & $\begin{array}{l}\text { Growth } \\
\text { pattern }\end{array}$ & Viability & $\begin{array}{l}\text { Doubling } \\
\text { time }\end{array}$ & $\begin{array}{l}\text { Cell } \\
\text { morphology }\end{array}$ \\
\hline SNU-306 & Adherent & 85 & 152 & Pleomorphic \\
\hline SNU-334 & $\begin{array}{c}\text { Floating } \\
\text { aggregates }\end{array}$ & 88 & 80 & Round to oval \\
\hline SNU-1528 & Adherent & 83 & 110 & Polygonal \\
\hline SNU-1553 & Adherent & 91 & 89 & Pleomorphic \\
\hline SNU-1581 & Adherent & 89 & 47 & $\begin{array}{l}\text { Spindle to } \\
\text { pleomorphic }\end{array}$ \\
\hline SNU-1958 & $\begin{array}{l}\text { Adherent/ } \\
\text { floating }\end{array}$ & 87 & 53 & $\begin{array}{l}\text { Polygonal, } \\
\text { round to oval }\end{array}$ \\
\hline SNU-2372 & Adherent & 82 & 78 & Polygonal \\
\hline
\end{tabular}

thermal cycler. Fresh PCR products were sequenced using a Taq dideoxy terminator cycle sequencing kit on an ABI 3730 DNA sequencer (Applied Biosystems).

Taxol cytotoxicity assay. A colorimetric assay using the tetrazolium salt 3-(4,5-dimethylthiazol-2-yl)-2,5-diphenyl tetrazolium bromide (Sigma-Aldrich) was used to assess the cytotoxicity of taxol (Sigma-Aldrich).

\section{Results}

A total of seven breast cancer cell lines derived from Korean patients were established in AR5 medium. Population doubling times ranged from $47-152 \mathrm{~h}$ and cell viability after thawing was about $85 \%$ (Table I). All cell lines were free of contamination from either bacteria or mycoplasma.

Three of the tumors were obtained from primary breast carcinomas, while SNU-1553 and SNU-2372 were obtained from pleural effusion, SNU-1581 from a pericardial effusion and SNU-1958 from ascitic fluid (Fig. 1F). The three tumors from primary breast cancer were infiltrating ductal carcinoma. All showed marked nuclear and histologic atypism. Ductal carcinoma in situ component was present in the cell lines derived from all patients except SNU-334. In the patient from whom the SNU-1581 cell line was derived, the stage IIA infiltrating ductal carcinoma had been removed 3 years prior to the occurrence of malignant pericardial effusion. In the patient from whom the SNU-1958 cell line was derived, stage IIA infiltrating ductal carcinoma was removed 10 years prior to the recurrence in the peritoneal cavity with ascites. In the patient from whom the SNU-2372 cell line was derived, multiple cervical, axillary lymph node, and chest wall recurrence was detected 1 month after resection of stage IIA breast cancer, and the cell line was established from the pleural effusion. Characteristics of the cell lines are summarized in Table II.

Table II and Fig. 1 summarize the morphologic observations. Briefly, SNU-306, SNU-1528, SNU-1553 and SNU-2372 grew in vitro as adherent monolayers, the SNU-334 grew as floating aggregates, and SNU-1581 and SNU-1958 cell lines grew as both floating aggregates and monolayers (Fig. 1A-E, G and H). 

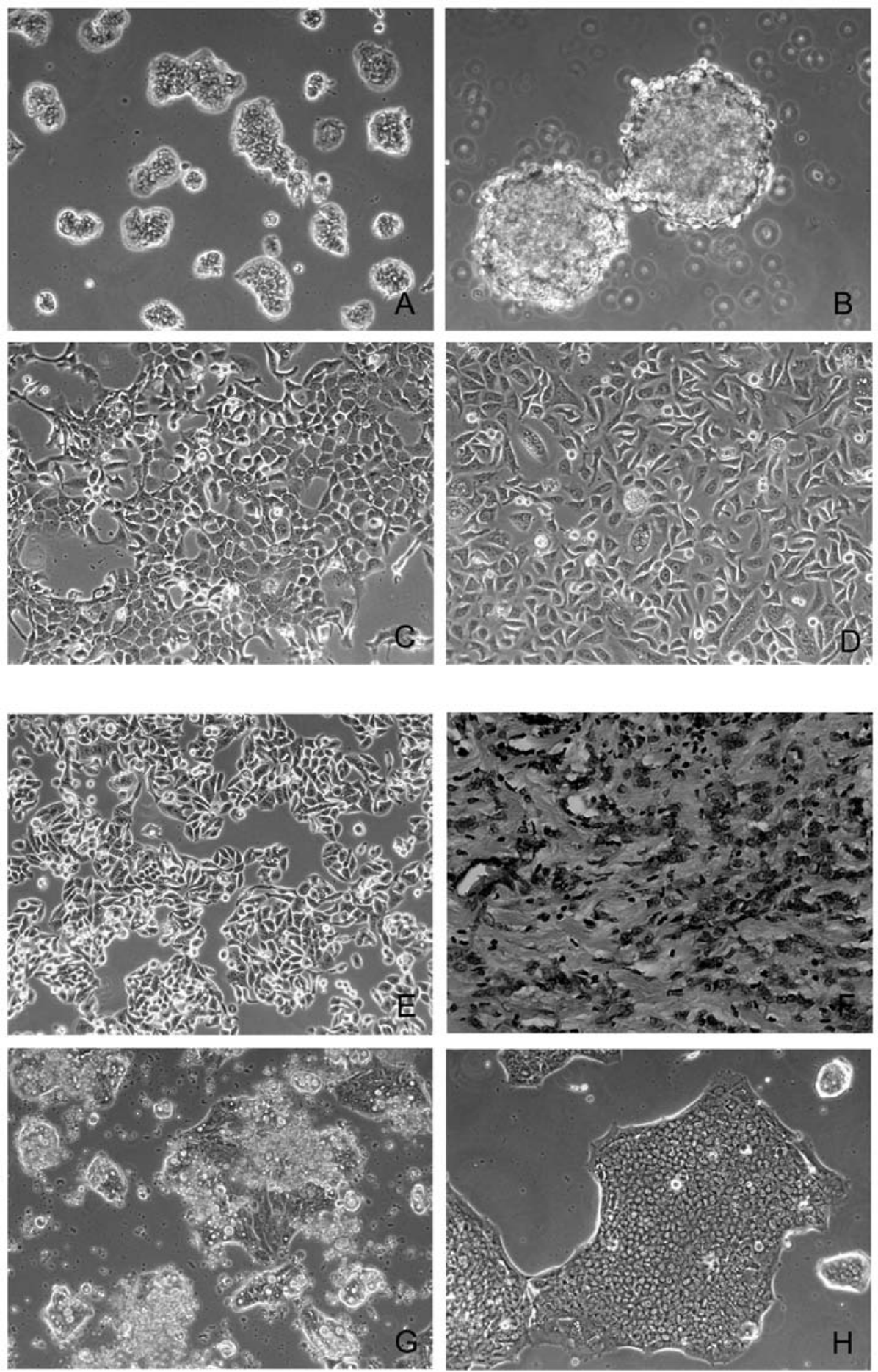

Figure 1. Morphology of the breast cancer cell lines in vivo and in vitro. (A) Phase-contrast photography of a tissue-culture specimen of the ductal carcinoma of the breast (SNU-306). The colonies of tightly packed cancer cells. (B) Phase-contrast photography of the tissue culture of the ductal carcinoma of the breast (SNU-334). The large floating aggregates consisted of round or oval cells. (C) Phase-contrast photography of the tissue culture of the breast ductal carcinoma (SNU-1528). The polygonal epithelial cells grew as monolayers. (D) Culture of the tissue specimen of the ductal carcinoma of the breast (SNU1553). The polymorphic cells with the prominent nucleoli and/or multinucleated cells. (E) Culture of the tissue specimen of the ductal carcinoma of the breast (SNU-1581). The polymorphic epithelial cells with the spindle or polygonal shapes growing as monolayers. (F) Original tumor of SNU-1581 showing infiltrating ductal carcinoma. (G) In vitro image of SNU-1958 cell line. SNU-1958 consisted of pleomorphic adherent cells and floating aggregates of cancer cells. (H) Culture image of SNU-2372 cells. These cells grew as monolayers with polygonal epithelial cells having prominent nucleoli.

SNU-306 cell line grew as various sized colonies consisting of tightly packed small cells (Fig. 1A). SNU-334 cells were round or oval (Fig. 1B). SNU-1528 epithelial cells were spindle- or polygonal-shaped (Fig. 1C). SNU-1553 cells were polygonal in shape and displayed prominent nucleoli; also some giant cells containing several nuclei were evident (Fig. 1D). SNU-1581 epithelial cells had a spindle or polygonal shape (Fig. 1E). SNU-1958 cells were pleomorphically shaped (Fig. 1G) and SNU-2372 cells were polygonal in shape and displayed prominent nucleoli (Fig. 1H). 
Table III. DNA fingerprinting analysis using 16 STR loci for the seven newly established breast cancer cell lines.

\begin{tabular}{lccccccc}
\hline Loci & SNU-306 & SNU-334 & SNU-1528 & SNU-1553 & SNU-1581 & SNU-1958 & SNU-2372 \\
\hline D8S1179 & 13,14 & 13,15 & 13,14 & 12 & 16 & & \\
D21S11 & 30 & 30,32 & $30,30.2$ & 30 & $30,32.2$ & & 11 \\
D7S820 & 11,12 & 10,11 & 11 & 12 & 8,10 & 8,11 & 12 \\
CSF1P0 & 11 & 12 & 9,10 & 11 & 10,11 & 10,13 & $15.2,18.2$ \\
D3S1358 & 15,17 & 15 & 16 & 17 & 16 & 15 & 9,11 \\
TH01 & 9 & 9 & 5.3 & 7,9 & 6,8 & & \\
D13S317 & 8,10 & 12 & 9 & 11 & 8 & 9,10 & \\
D16S539 & 13 & 9 & 9,11 & 13 & 10 & & 8 \\
D2S1338 & 25 & 17 & 25 & 19 & 18 & & \\
D19S433 & 13 & $14,14.2$ & 14 & 13,14 & 13 & & \\
vWA & 16,17 & 18 & 17 & 16,17 & 17 & 16,17 & 8 \\
TPOX & 8 & 11 & 11 & 11,12 & 8,9 & 13 & 8 \\
D18S51 & 13 & 14,15 & 18 & 13 & 13 & & \\
Amelogenin & $\mathrm{X}, \mathrm{X}$ & $\mathrm{X}, \mathrm{X}$ & $\mathrm{X}, \mathrm{X}$ & $\mathrm{X}, \mathrm{X}$ & $\mathrm{X}, \mathrm{X}$ & $\mathrm{X}, \mathrm{X}$ & $\mathrm{X}, \mathrm{X}$ \\
D5S818 & 11 & 11 & 11,12 & 10 & 12,13 & 9,11 & 12 \\
FGA & 23 & 20 & 24 & 22,23 & 19,24 & 19,21 & 25 \\
\hline
\end{tabular}

\section{D1S1586}

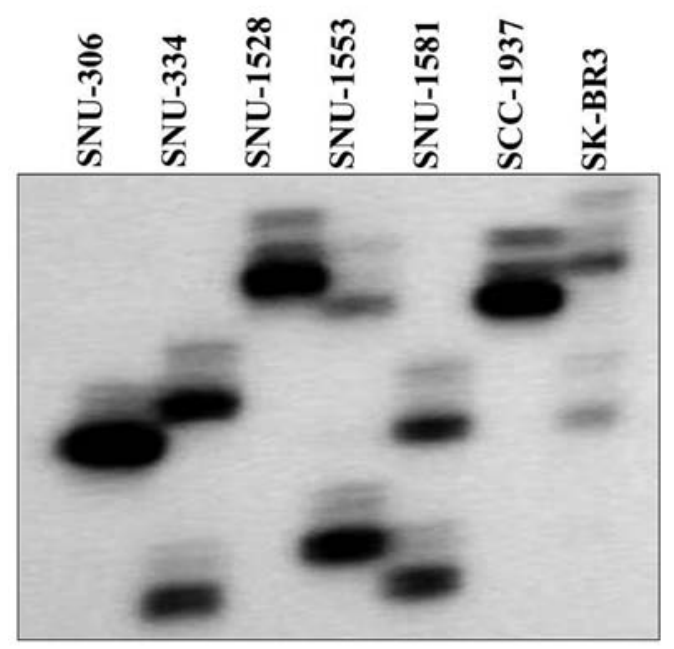

Figure 2. DNA fingerprinting analysis of breast cancer cell lines. DNA-fingerprinting analysis of seven breast cancer cell lines using the highly-polymorphic microsatellite marker D1S1586. The newly established SNU breast cancer cell lines are unique and unrelated.

Use of two highly polymorphic microsatellite markers showed that the seven breast cancer cell lines were unique and unrelated (Fig. 2), and helped exclude the possibility of crosscontamination among the cell lines. DNA fingerprinting using the AmpFISTR identifiler PCR amplification kit revealed the heterogeneous distribution of 15 tetranucleotide repeat loci and Amelogen gender determining marker in each cell line, and confirmed the lack of cross-contamination (Table III).

In RT-PCR analysis, ER- $\alpha$ was expressed in SNU-306, SNU-334, SNU-1528, SNU-1553 and SNU-1581. $P R$ was expressed only in the SNU-306 and $C$-erbB2 was not expressed in any of the cell lines (Fig. 3A). These combinations revealed three cell line groups: $E R-\alpha$ and $P R$ expression without $C$-erbB2 expression (SNU-306), ER- $\alpha$ expression without $P R$ and $C$-erbB2 expression (SNU-334, SNU-1528, and SNU-1553), and no expression of $E R-\alpha, P R$ and $C$-erbB2 (triple-negative; SNU-1958 and SNU-2372) (Table IV). In western blot analysis, $C$-erbB2 was highly expressed in SNU-334 and weakly expressed in SNU-1528, SNU-1553 and SNU-1958 cell lines. $E R-\alpha$ was expressed in SNU-334, SNU-1581, SNU-1958 and SNU-2372 cell lines. $P R$ was expressed in the SNU-334, SNU-1553, SNU-1581, SNU-1958 and SNU-2372 cell lines (Fig. 3B).

COX-2 was expressed in SNU-306, SNU-1528, SNU-1958 and SNU-2372. MDR1 was highly overexpressed in the SNU-1958 and weakly expressed in the SNU-1581. MXR was expressed in SNU-306 and SNU-1553. E-cadherin was not expressed in the SNU-1581 (Fig. 4). SNU-1528 had a mutation in exon 4. Specifically, cells displayed an inframe deletion of 42 base pairs from codons 93-109 in exon 4 (Fig. 5). SNU-306, SNU-334 and SNU-1581 possessed arginine at codon 72 and the SNU-1553 cell line harbored proline at codon 72 . There were no mutations in the EGFR gene in these cell lines (data not shown). SNU-1528 displayed more cross resistance for paclitaxel than SNU-334, SNU-1533, and SNU-1581 cell lines (data not shown). Taxol $\mathrm{IC}_{50}(\mathrm{nM} / \mathrm{ml})$ values were $>1161.298$ for SNU-1528, 41.905 \pm 9.264 for SNU-1553, 41.063 \pm 4.681 for SNU-334, and 26.432 \pm 11.397 for SNU-1581.

\section{Discussion}

Much of the current knowledge on biology of breast carcinomas is based on in vivo and in vitro studies performed with breast cancer cell lines (4). The present study reports on seven cell lines obtained from three primary carcinomas, two 
Table IV. Expressions of genes in breast cancer cell lines.

\begin{tabular}{|c|c|c|c|c|c|c|c|}
\hline Cell line & C-erbB $2^{a}$ & $E R-\alpha^{a}$ & $\mathrm{PR}^{\mathrm{a}}$ & COX -2 & MDR1 & MXR & E-cadherin \\
\hline SNU-306 & $-/-$ & $+/-$ & $+/-$ & + & - & - & + \\
\hline SNU-334 & $-/+$ & $+/+$ & $-/+$ & - & - & - & + \\
\hline SNU-1528 & $-/+$ & $+/-$ & $-/-$ & + & - & - & + \\
\hline SNU-1553 & $-/+$ & $+/-$ & $-/+$ & - & - & + & + \\
\hline SNU-1581 & $-/-$ & $+/+$ & $-/+$ & - & - & - & - \\
\hline SNU-1958 & $-/+$ & $-/+$ & $-/+$ & - & + & - & + \\
\hline SNU-2372 & $-/-$ & $-/+$ & $-/+$ & + & - & - & + \\
\hline
\end{tabular}

${ }^{\mathrm{a}}$ Expression of mRNA/protein.
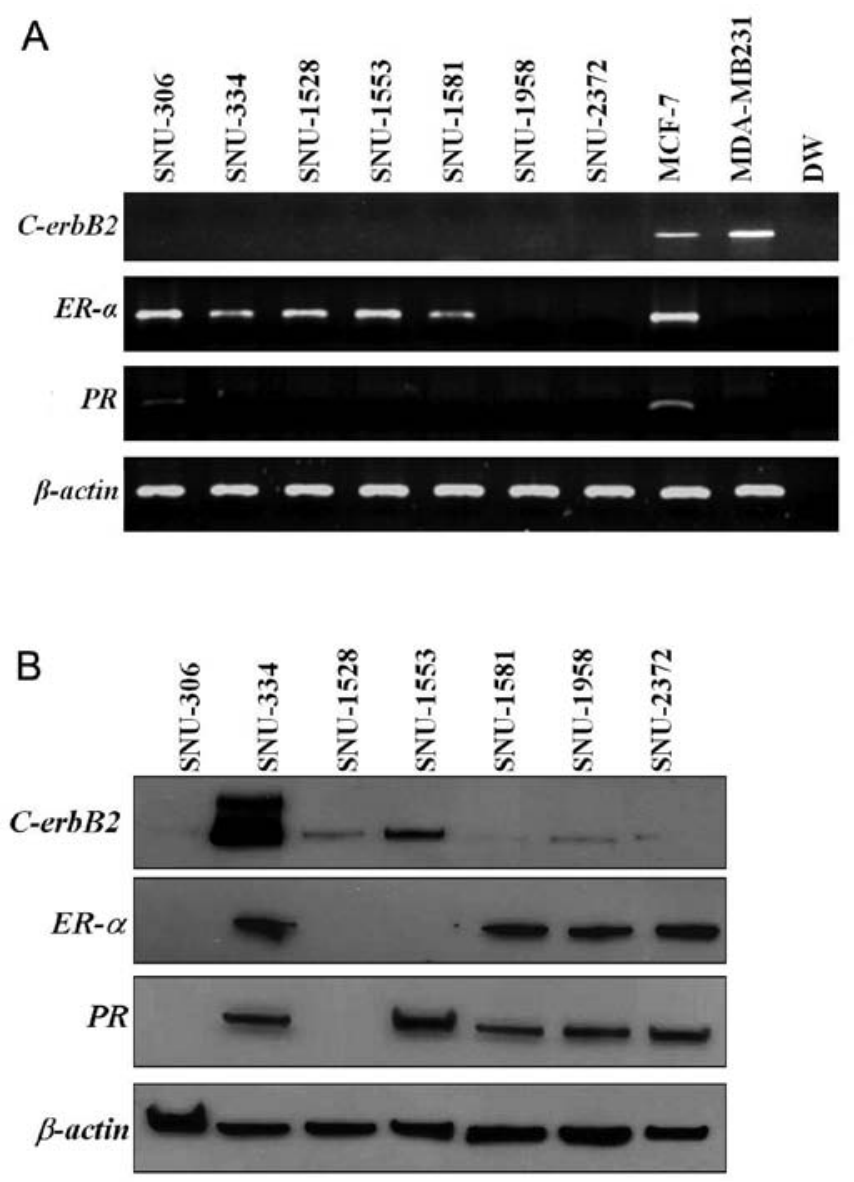

Figure 3. Expressions of $C$-erbB2, $E R$ - $\alpha$ and $P R$ genes. (A) RT-PCR analysis of $C$-erbB2, $E R$ - $\alpha$ and $P R$ genes in SNU breast cancer cell lines. $\beta$-actin was amplified as an internal control (30 cycles of PCR). (B) Western blot analysis of $C$-erbB2, ER- $\alpha$ and $P R$ genes in SNU breast cancer cell lines.

pleural effusions, one pericardial effusion and one ascitic fluid. Each cell line was shown to be unique at the DNA level using fingerprinting analysis, two highly polymorphic markers, and 15 short tandem repeat markers. None of the cell lines was contaminated by mycoplasma or bacteria.

The presence or absence of tumor growth factor receptors (specifically, $E R, P R$ and $C$-erbB2) is important for prediction of prognosis and treatment selection in breast cancer patients.

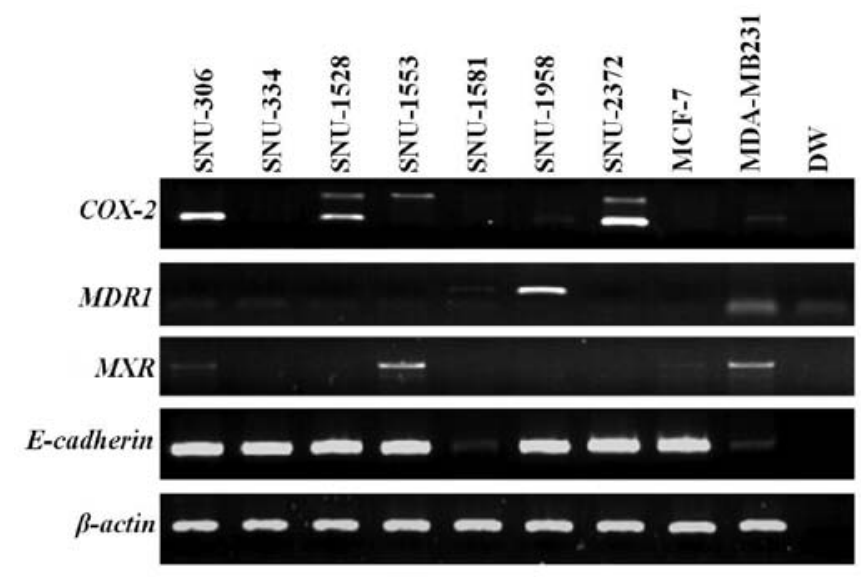

Figure 4. mRNA expressions of $C O X-2, M D R 1, M X R$ and E-cadherin genes. RT-PCR analysis of COX-2, MDR1,MXR and E-cadherin genes in SNU breast cancer cell lines. $\beta$-actin was amplified as an internal control (30 cycles of PCR).

$E R-\alpha$ remains a very effective biologic target for breast cancer treatment and prevention, and anti-estrogens are incorporated into the recommended treatment of all $E R$ - $\alpha$-expressing tumors. Estrogen is a steroid hormone that has a profound proliferative effect on normal human mammary epithelium through its activation of $E R-\alpha$, a classic nuclear hormone receptor. $E R-\alpha$ is overexpressed in as many as $70 \%$ of breast cancers; amplification of the ER- $\alpha$ gene appears to be a prominent mechanism, although it does not account for all cases of ER- $\alpha$ overexpression (1).

The significance of $P R$ expression in breast cancer has been less recognized. $P R$ is an estrogen-dependent protein synthesized after the stimulation of target cells with estrogen. $E R$ - $\alpha$-negative and $P R$-positive breast cancer cases carry the worst prognosis. Detection of overexpressed $P R$ in tumors serves as a functional indicator of an intact ER pathway, even if the tumor is reported as $E R$ - $\alpha$-negative.

Cumulative data from a number of studies have revealed that steroid receptors are distributed in breast tumors as follows: 50-60\% $\mathrm{ER}^{+} / \mathrm{PR}^{+} ; 10-20 \% \mathrm{ER}^{+} / \mathrm{PR}^{-} ; 5-15 \% \mathrm{ER}^{-} / \mathrm{PR}^{+}$; and $15-25 \% \mathrm{ER}^{-} / \mathrm{PR}^{-}$. In the present study, the steroid receptor combinations were: $\mathrm{ER}^{+} / \mathrm{PR}^{+}(\mathrm{SNU}-306), \mathrm{ER}^{+} / \mathrm{PR}^{-}$(SNU-334, SNU-1528, SNU-1553 and SNU-1581), and ER/PR- (SNU1958 and SNU-2372) in RT-PCR analysis (Fig. 3A); $\mathrm{ER}^{+} /$ 
wild type - SNU-306

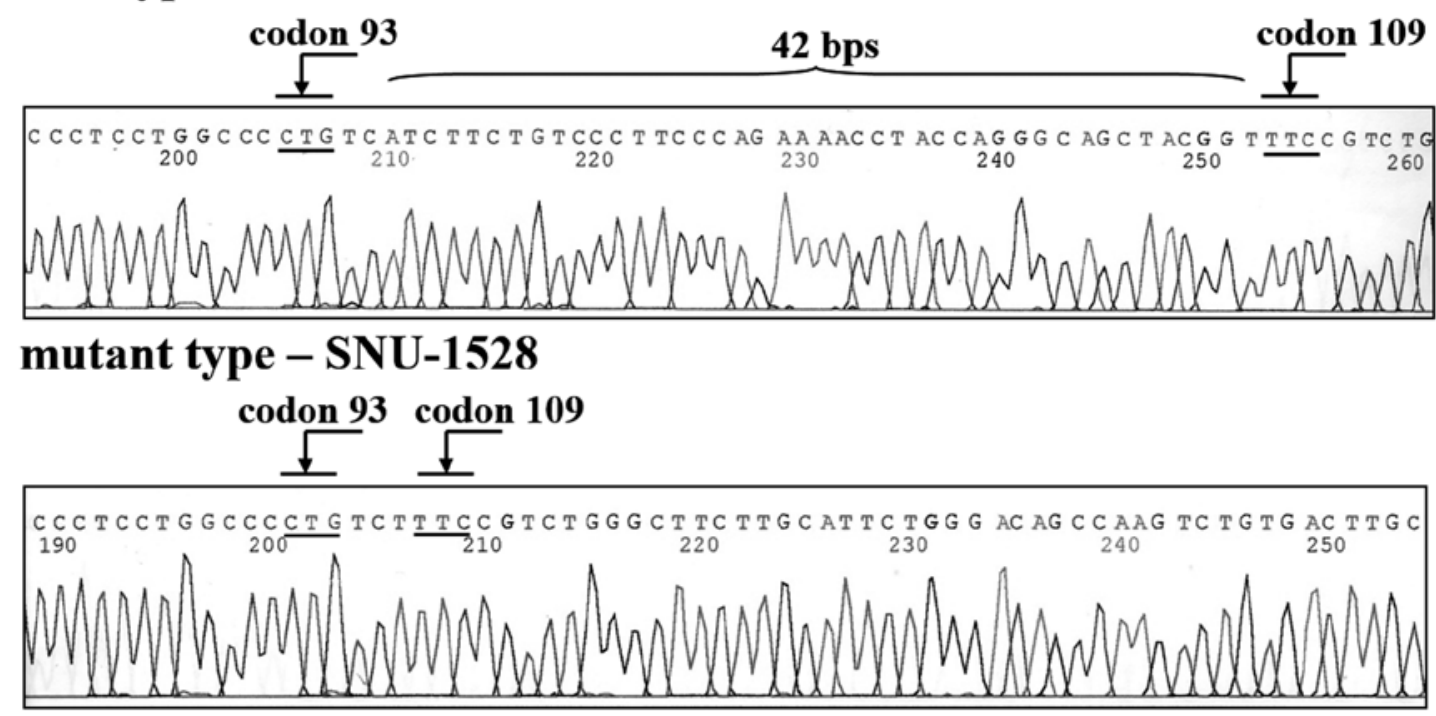

'inframe deletion' of 42 base pairs (14 codons) between codons 93 and 109

Figure 5. Mutations of $p 53$ gene. Mutational analysis of the $p 53$ gene in the breast cancer cell lines. Upper panel, DNA sequencing analysis of exon 4 in SNU-306 cell line. Lower panel, DNA sequencing analysis of exon 4 in SNU-1528 cell line. SNU-1528 cell line had an inframe deletion of 42 base pairs from codon 93 to codon 109 in exon 4.

$\mathrm{PR}^{+}\left(\mathrm{SNU}-334, \mathrm{SNU}-1581, \mathrm{SNU}-1958\right.$ and SNU-2372), $\mathrm{ER}^{+} /$ $\mathrm{PR}^{-}$(none), ER-/PR ${ }^{+}$(SNU-1553) and ER-/PR- (SNU-306 and SNU-1528) in western blot analysis (Fig. 3B). In this study, mRNA levels and their corresponding protein levels was not significantly correlated. Discordant protein and mRNA expression has been reported in literature $(19,20)$. This discrepancy might reflect differences in the regulation of gene products by transcriptional, translational and post-translational mechanism among different cells.

$C$-erbB2, which is localized on chromosome 17q12-21 and encodes for a transmembrane tyrosine kinase receptor protein, is a useful target for the monoclonal anti-C-erbB2 antibody trastuzumab (Herceptin). In vitro, overexpression of $C$-erbB2 in epithelial cells affects the regulation of cell proliferation, apoptotic pathway, motility and adhesion (21). The absence of $C$-erbB2 results in impaired ductal growth accompanying puberty in mouse mammary glands (22). $C$-erbB2 amplification and/or protein overexpression, which is apparent in $20-30 \%$ of invasive breast cancers, is clearly associated with accelerated cell growth and proliferation, as well as an increased risk of disease recurrence with shortened overall patient survival. At a molecular level, amplification is associated with deregulation of G1/S phase cell cycle control via upregulation of cyclins D1, E and cdk6, as well as p27 degradation. $C$-erbB2 also interacts with important second messengers including SH2 domaincontaining proteins (e.g., Src kinases) that provide potential additional targets for breast cancer therapy (1). In several studies, $C$-erbB2 amplification/overexpression in metastatic breast cancer has been shown to be an independent marker of response to the monoclonal anti-C-erbB2 antibody for trastuzumab. $C$-erbB2 was not expressed in any of the seven cell lines by RT-PCR analysis in this study. However, this gene was highly expressed in SNU-334 and weakly expressed in
SNU-1528, SNU-1553 and SNU-1958 cell lines by western blot analysis. $C$-erbB2 was detected in a primary tumor of SNU-1553 by immunohistochemistry (data not shown). This discrepancy between mRNA and protein expression might also reflect transcriptional or post-translational modulation of $c$-erbB2 expression.

$C O X-2$ expression is induced during inflammation by pro-inflammatory cytokines and growth factors, and is detectable in most tissues. $C O X-2$ overexpression is common to a variety of human malignancies including cancer of the colon, and promotes tumor cell growth, angiogenesis, tumor invasion and metastasis (reviewed in ref. 23). Overexpression of $C O X-2$ is significantly associated with reduced disease-free survival but not with overall disease-specific survival. In mouse models, $C O X-2$ expression is associated with lymph node metastasis. $C O X-2$ has also been implicated in vascular endothelial growth factor production that stimulates angiogenesis, with $C O X-2$ antagonists possessing anti-angiogenic activity. Inhibition of $C O X-2$ can reverse resistance to apoptosis. Reduced breast cancer incidence with the use of non-steroidal anti-inflammatory drugs has been reported (24). In our study, COX-2 was overexpressed in four of the seven cell lines (SNU-306, SNU-1528, SNU-1958 and SNU-2372) (Fig. 4).

The most frequently reported alteration associated with multidrug resistance is the increased expression of a $170-\mathrm{kDa}$ membrane P-glycoprotein encoded by the MDRl gene. P-glycoprotein functions as an energy-dependent drug efflux pump that reduces intracellular drug accumulation, thereby causing resistance to many structurally different drugs (14), and was shown by us to be highly overexpressed in SNU-1958 cells and weakly expressed in SNU-1581 cells.

$M X R$, also called $A B C G 2, A B C P$ or $B C R P$ is an $\mathrm{ABC}$ transporter that has an N-terminal ATP binding domain and 
a C-terminal transmembrane domain (15). BCRP/MXR overexpression has been reported in various drug-resistant cells selected with mitoxantrone, doxorubicin and topotecan. $B C R P / M X R$ presumably acts as an efflux pump, resulting in decreased intracellular concentrations. $B C R P / M X R$ was overexpressed in SNU-306 and SNU-1553 cell lines (Fig. 4). E-cadherin gene located on chromosome 16q22.1 encodes a protein that is important in the maintenance of the epithelial phenotype mediated by a $\mathrm{Ca}^{2+}$-dependent, homotypic cell-cell adhesion. The gene has been termed a 'metastasis suppressor' gene, because the E-cadherin protein can suppress tumor cell invasion and metastasis. E-cadherin gene expression is reduced or silenced in carcinomas of the breast and liver, and many cell lines including those from colon, stomach and prostate (12). Of the seven presently studied breast cancer cell lines, E-cadherin was not expressed in SNU-1581 cells (Fig. 4).

p53 tumor suppressor protein is the most commonly mutated protein in diverse cancers and has been implicated in the late stage of malignant transformation (25). In this study, a p53 mutation comprising an inframe deletion of 42 nucleotides from codons 93-109 in exon 4 was evident in the SNU-1528 cell line. In human populations, the $p 53$ gene is polymorphic at amino acid 72 of the encoded protein. Arg72 variant was found in the SNU-306, SNU-334, and SNU-1581 cell lines, and a Pro72 variant was found in the SNU-1553 cell line. $p 53$ with Pro72 is structurally different from $p 53$ with $\operatorname{Arg} 72$, as this is reflected by its altered electrophoretic mobility; $p 53$ with Arg72 migrates more rapidly than $p 53$ with Pro72 (26). The Arg72 variant also induces apoptosis markedly better than the Pro72 variant, and the two polymorphic variants of $p 53$ are functionally distinct. These differences may influence cancer risk or treatment, but most studies on $p 53$ have involved Pro72 variants because it was the first form of human $p 53$ to be cloned, whereas few functional studies have included the $\operatorname{Arg} 72$ form (27). In breast cancer patients, Arg72 homozygosity is associated with breast cancers and could be a potential risk factor for tumorigenesis of the breast (26). Characterization of polymorphic variation of $p 53$ in the seven cell lines will be helpful for discerning functional differences of breast cancer by variation of $p 53$.

Many of the currently used breast cancer cell lines were established in the late 1970s, and MCF-7, T-47D and MDA-MB-231, account for more than two-thirds of all abstracts reporting studies on breast cancer cell lines. These cell lines were not derived from primary breast tumors, but from tumor metastases, especially aspirates of pleural effusions. This means that the majority of commonly used cell lines are derived from more aggressive and often metastatic tumors, rather than the primary lesion, hence there is legitimate reason to question the representativeness of these cell lines. Well-characterized cell lines derived from primary breast tumors will help alleviate this situation.

The present study report the cellular and molecular characteristics of the seven newly established cell lines designated, SNU-306, SNU-334, SNU-1528, SNU-1553, SNU-1581, SNU-1958 and SNU-2372, which were derived from breast carcinoma patients. These well-characterized breast cancer cell lines, which include two triple-negative cell lines, will be useful for the study of breast cancer biology.

\section{Acknowledgements}

This study was supported by a research grant from the Korean Cell Line Research Foundation (2009) and the Cancer Research Institute, Seoul National University (2002) and Priority Research Centers Program through the NRF grant funded by the MEST (no. 2009-0093820).

\section{References}

1. DeVita VT, Lawrence TS and Rosenberg SA: DeVita, Hellman, and Rosenberg's Cancer: Principles \& Practice of Oncology. Wolters Kluwer/Lippincott Williams \& Wilkins, Philadelphia, PA, 2008.

2. Neve RM, Chin K, Fridlyand J, et al: A collection of breast cancer cell lines for the study of functionally distinct cancer subtypes. Cancer Cell 10: 515-527, 2006.

3. Gazdar AF, Kurvari V, Virmani A, et al: Characterization of paired tumor and non-tumor cell lines established from patients with breast cancer. Int J Cancer 78: 766-774, 1998.

4. Lacroix M and Leclercq G: Relevance of breast cancer cell lines as models for breast tumours: an update. Breast Cancer Res Treat 83: 249-289, 2004.

5. Burdall SE, Hanby AM, Lansdown MR and Speirs V: Breast cancer cell lines: friend or foe? Breast Cancer Res 5: 89-95, 2003.

6. Park JG, Lee JH, Kang MS, et al: Characterization of cell lines established from human hepatocellular carcinoma. Int J Cancer 62: 276-282, 1995.

7. Ku JL, Yoon KA, Kim IJ, et al: Establishment and characterisation of six human biliary tract cancer cell lines. Br J Cancer 87: 187-193, 2002.

8. Koh CS, Ku JL, Park SY, et al: Establishment and characterization of cell lines from three human thyroid carcinomas: responses to all-trans-retinoic acid and mutations in the BRAF gene. Mol Cell Endocrinol 264: 118-127, 2007.

9. Takano N, Iizuka N, Hazama S, Yoshino S, Tangoku A and Oka M: Expression of estrogen receptor-alpha and -beta mRNAs in human gastric cancer. Cancer Lett 176: 129-135, 2002.

10. Brys M, Wojcik M, Romanowicz-Makowska $H$ and Krajewska WM: Androgen receptor status in female breast cancer: RT-PCR and Western blot studies. J Cancer Res Clin Oncol 128: 85-90, 2002.

11. O-charoenrat P, Rhys-Evans PH, Archer DJ and Eccles SA: $\mathrm{C}$-erbB receptors in squamous cell carcinomas of the head and neck: clinical significance and correlation with matrix metalloproteinases and vascular endothelial growth factors. Oral Oncol 38: 73-80, 2002.

12. Melki JR, Vincent PC, Brown RD and Clark SJ: Hypermethylation of E-cadherin in leukemia. Blood 95: 3208-3213, 2000.

13. Hase T, Yoshimura R, Matsuyama M, et al: Cyclooxygenase-1 and -2 in human testicular tumours. Eur J Cancer 39: 2043-2049, 2003.

14. Yang CH, Schneider E, Kuo ML, Volk EL, Rocchi E and Chen YC: BCRP/MXR/ABCP expression in topotecan-resistant human breast carcinoma cells. Biochem Pharmacol 60: 831-837, 2000.

15. Rajendra R, Gounder MK, Saleem A, et al: Differential effects of the breast cancer resistance protein on the cellular accumulation and cytotoxicity of 9-aminocamptothecin and 9-nitrocamptothecin. Cancer Res 63: 3228-3233, 2003.

16. Yoo BC, Hong SH, Ku JL, et al: Galectin-3 stabilizes heterogeneous nuclear ribonucleoprotein Q to maintain proliferation of human colon cancer cells. Cell Mol Life Sci 66: 350-364, 2009.

17. Kang MS, Lee HJ, Lee JH, et al: Mutation of p53 gene in hepatocellular carcinoma cell lines with HBX DNA. Int J Cancer 67: 898-902, 1996.

18. Tokumo M, Toyooka S, Kiura K, et al: The relationship between epidermal growth factor receptor mutations and clinicopathologic features in non-small cell lung cancers. Clin Cancer Res 11: 1167-1173, 2005.

19. Chen G, Gharib TG, Huang CC, et al: Discordant protein and mRNA expression in lung adenocarcinomas. Mol Cell Proteomics 1: 304-313, 2002. 
20. Wang G, Lai FM, Lai KB, et al: Discrepancy between intrarenal messenger RNA and protein expression of ACE and ACE2 in human diabetic nephropathy. Am J Nephrol 29: 524-531, 2008.

21. Fritz P, Cabrera CM, Dippon J, et al: c-erbB2 and topoisomerase IIalpha protein expression independently predict poor survival in primary human breast cancer: a retrospective study. Breast Cancer Res 7: R374-R384, 2005.

22. Shyamala G, Chou YC, Cardiff RD and Vargis E: Effect of c-neu/ErbB2 expression levels on estrogen receptor alpha-dependent proliferation in mammary epithelial cells: implications for breast cancer biology. Cancer Res 66: 10391-10398, 2006.

23. Swamy MV, Herzog CR and Rao CV: Inhibition of COX-2 in colon cancer cell lines by celecoxib increases the nuclear localization of active p53. Cancer Res 63: 5239-5242, 2003.
24. Nassar A, Radhakrishnan A, Cabrero IA, Cotsonis G and Cohen C: COX-2 expression in invasive breast cancer: correlation with prognostic parameters and outcome. Appl Immunohistochem Mol Morphol 15: 255-259, 2007.

25. Hollstein M, Sidransky D, Vogelstein B and Harris CC: p53 mutations in human cancers. Science 253: 49-53, 1991.

26. Papadak is EN, Dokianakis DN and Spandidos DA: p53 codon 72 polymorphism as a risk factor in the development of breast cancer. Mol Cell Biol Res Commun 3: 389-392, 2000.

27. Dumont P, Leu JI, Della Pietra AC III, George DL and Murphy M: The codon 72 polymorphic variants of p53 have markedly different apoptotic potential. Nat Genet 33: 357-365, 2003. 